\title{
Erratum to: Morphogenesis of the Sign
}

\author{
David Piotrowski
}

\section{Erratum to:}

D. Piotrowski, Morphogenesis of the Sign, Lecture Notes in Morphogenesis, DOI 10.1007/978-3-319-55325-2

The original version of the book was inadvertently published with errors in Chapters 3, 5-8 and back matter which have to be corrected. The erratum book has been updated with the changes.

The updated online version for these chapters can be found at http://dx.doi.org/10.1007/978-3-319-55325-2_3

http://dx.doi.org/10.1007/978-3-319-55325-2_5

http://dx.doi.org/10.1007/978-3-319-55325-2_6

http://dx.doi.org/10.1007/978-3-319-55325-2_7

http://dx.doi.org/10.1007/978-3-319-55325-2_8

http://dx.doi.org/10.1007/978-3-319-55325-2 